\title{
Poster Presentation
}

MS83.P34

\section{9,9'-Spirobifluorene Based MOFs: Synthesis, Structure, Catalytic Properties}

\author{
$\underline{\text { N. Snejko }^{1}}{ }^{1}$ M. Iglesias ${ }^{1}$, Á. Monge ${ }^{1}$, Á. Benito-Hernández ${ }^{1}$, M. Pintado ${ }^{2}$, M. Medina ${ }^{1}$, E. Gutiérrez-Puebla $^{1}$ \\ ${ }^{1}$ ICMM-CSIC, Madrid, Spain, ${ }^{2}$ IQOG-CSIC, Madrid, Spain
}

The 9,9'-spirobi[fluorene]-3,3',6,6'-tetracarboxylic acid (H4SBF), a ligand based on the spirobifluorene (SBF) core, was used as a ligand for the synthesis of the MOFs [Co(H2SBF)Phen(H2O)]n (1), and [M(H2SBF) $\left.\left(4,4^{\prime}-\mathrm{Bipy}\right)\right] n(\mathrm{M}=\mathrm{Co}, \mathrm{Ni}, \mathrm{Cu})(2)$. The ligand H4SBF is based on the spirobifluorene (SBF) core: the interest in the SBF platform is due to its application as chiral ligand in organic electronics, as solid state laser or in third-order nonlinear optics. The MOFs with H4SBF have been obtained by hydrothermal reaction of H4SBF, the corresponding $\mathrm{MCl} 2$ and the base (Phen or 4,4'-Bipy) in a molar ratio H4SBF : M2+ : base = 1:1:1. The obtained MOFs are stable in air and thermally stable up to $\sim 400^{\circ} \mathrm{C}$. The MOFs $2(\mathrm{M}=\mathrm{Co}, \mathrm{Ni}, \mathrm{Cu}$ ) are isostructural (proved by DRXP data). Only for 1 and 2 (M=Ni) the crystals were obtained apt for crystallographic study. The Ni compound crystallizes in monoclinic system, $\mathrm{Cc}$ space group with cell parameters: $40.8251 \AA, 12.0031 \AA, 11.8383 \AA$ and $\beta=104.398^{\circ}$, vol. $5618.89 \AA 3$. Ni metal center is hexacoordinated in an octahedral environment with five $\mathrm{O}$ atoms of two ligands and one $\mathrm{N}$ atom from 4,4- Bipy, which means that there is another $\mathrm{N}$ atom not coordinated to metal center. The structure of 2 is $2 \mathrm{D}$ with interlayer $\mathrm{H}$ bonds, which built up a supramolecular 3D net. The Co compound is triclinic, P-1 space group with cell parameters: $10.9775 \AA, 12.7231 \AA, 14.2381 \AA, \alpha=65.203^{\circ}, \beta=87.528^{\circ}, \gamma=72.947^{\circ}$, vol. 1718.6 А̊3. Like Ni compound, Co metal center is hexacoordinated in an octahedral environment with three $\mathrm{O}$ atoms of one ligand, two $\mathrm{N}$ atoms from Phen and one water coordinated molecule, which builds up a 2D structure. To test the catalytic ability, the obtained MOFs were used to oxidize styrene molecules with tert-butyl hydroperoxide oxidant. Styrene was fully oxidized into its epoxidized product by 1 in $\mathrm{CH} 2 \mathrm{Cl} 2$ in $6 \mathrm{~h}$. Under the same conditions, 1 can oxidize the most inert cyclohexane substrate at $60{ }^{\circ} \mathrm{C}$ with $80.6 \%$ substrate conversion.
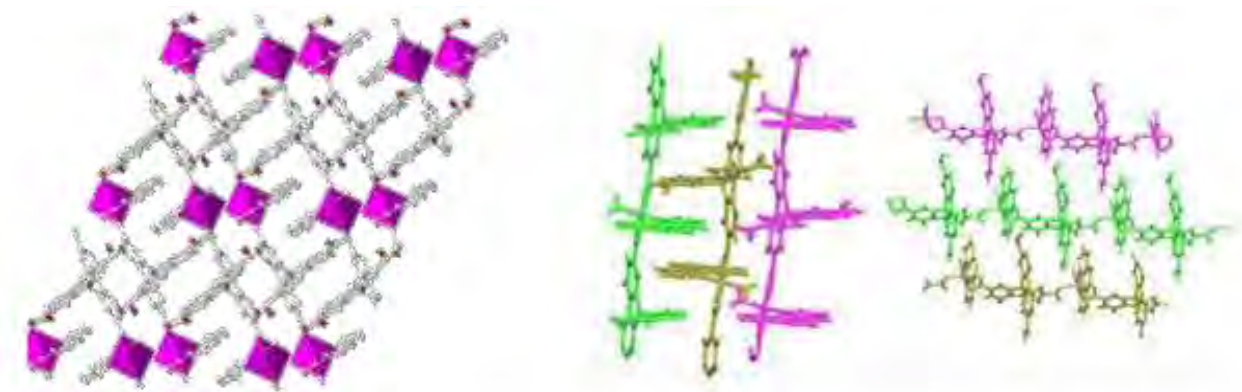

Figure 1. View along [100] (left) and the covalent net (right) formed by $\mathrm{Co}\left(\mathrm{H}_{2} \mathrm{SBF}\right)($ Phen $)\left(\mathrm{H}_{2} \mathrm{O}\right)$ chains running along the [100] direction in an A B C sequence.

Keywords: Metal-Organic Frameworks, Catalysis 